\title{
An analysis of what has been "lost" in the interpretation and transcription process of selected TRC testimonies*
}

\author{
Z. Bock, N. Mazwi, S. Metula, and N. Mpolweni-Zantsi \\ Department of Linguistics and Department of Xhosa, University of the Western Cape, \\ Private Bag X17, Bellville 7535. E-mail: zbock@uwc.ac.za, nzantsi@uwc.ac.za
}

\section{Introduction}

The Truth and Reconciliation Commission (henceforth "TRC" or "the Commission") emerged from the Kempton Park negotiations as a way of dealing with South Africa's past and promoting national unity and reconciliation. The Commission, established by the Promotion of National Unity and Reconciliation Act No. 35 of 1994 and promulgated by parliament on 16 December 1995, aimed to establish "as complete a picture as possible" of the injustices committed in the past (Truth and Reconciliation of South Africa Report 1998:104). At the same time, it was hoped that the work of the TRC would enable victims of human rights abuses in South Africa to "become more visible and more valuable citizens through the public recognition and official acknowledgement of their experiences" and that "those responsible for violations of human rights could also be held responsible for their actions" (ibid:110).

The question arises as to what exactly is meant by "as complete a picture as possible". What is meant by "truth"? And whose truth is intended? In the debates that took place before and during the life of the Commission, the understanding of 'truth' came to be seen as a more complex notion and in its final report, the TRC explored four notions of truth: factual or forensic truth; personal or narrative truth; social or "dialogue" truth; and healing and restorative truth (ibid:110). "Factual or forensic truth" refers to the scientific 
or legal notion of truth as factual corroborated evidence or "what happened to whom, where, when and how, and who was involved?" (ibid:111). "Personal or narrative truth" refers to a more subjective truth and attempts to validate the individual experiences "of people who had previously been silenced or voiceless" (ibid:112). It sought "to capture the widest possible record of people's perceptions, stories, myths and experiences" or as the TRC's chairperson, Archbishop Desmond Tutu, expressed it, to give everyone "a chance to say his or her truth as he or she sees it" (ibid:112). Social truth is "established through interaction, discussion and debate" and aims to promote "transparency, democracy and participation in society ... as a basis for affirming human dignity and integrity" (ibid:113-114). Lastly, healing and restorative truth was central to the work of the Commission and refers to "the kind of truth that places facts and what they mean within the context of human relationships". To this end, "acknowledgement" or the placing of information on public record was essential as a means of bringing about healing and a restoration of human dignity (ibid:114).

It is with the above conceptualisation of truth in mind that this research project was conceived. It is the contention of this paper that the official TRC records themselves only allow access to a limited truth. The majority of researchers using the TRC records have access only to the official version of the testimonies which are published in English on the TRC website ${ }^{1}$ (see, for example, Verdoolaege 2002). Many of these testimonies are based on simultaneous interpretations into English given on the day of the hearing. In this paper, we argue that these records are inadequate in many ways and that a number of "truths", both of the narrative and factual nature, have inevitably been lost through the interpretation and transcription process. In the testimonies, we examine some significant omissions and "errors" in the official TRC record. This loss of accuracy not only compromises to an extent the goals of the TRC, namely "to establish as complete a picture as possible", but also casts a measure of doubt on the value of some TRC scholarship. Researchers using these records would therefore be advised to check them against the original testimonies in the language in which they were given. It is the aim of this paper to analyse "what has been lost" in the interpretation and transcription process of two TRC testimonies. 


\section{Contextual information}

Thousands of South Africans brought their stories to the TRC, and these stories give a detailed insight into the forms and nature of oppression that were suffered under apartheid. Under its mandate, the TRC limited itself to the period between 1 March 1960 and 10 May 1994. Of the 21298 testimonies received, the TRC selected a number of representative testimonies for public hearings. There were three kinds of TRC hearings: the Human Rights Violations hearings which focussed on the victims, the Amnesty Hearings which dealt with perpetrators, and the Institutional or Special Hearings which focussed on either an event (such as the Gugulethu Seven) or a particular constituency, such as Women, Youth or the Business Community (Truth and Reconciliation of South Africa Report 1998).

In line with the TRC mandate to allow people to communicate in the language of their choice (see Promotion of National Unity and Reconciliation Act of 1996 sections 11(b) and 11(f)), the TRC had to set up an interpreting service of an extent and scope previously unseen in South Africa (Du Plessis and Wiegand 1998; Lotriet 1998). Each testimony was simultaneously interpreted into English and Afrikaans (if requested) and into one or two of the African languages spoken in the region (Du Plessis and Wiegand 1998:28).

The Language Facilitation Programme of the University of the Free State was contracted to hire, train and manage the interpreters for the TRC hearings. The Language Facilitation Programme, in conjunction with its Flemish partner, Televic, recruited and trained 21 candidates who, together with a number of freelance interpreters, provided the interpreting service.

Du Plessis and Wiegand (1998) and Lotriet (1998) refer to the difficulties of setting up this service. As this was the first time in South Africa's history that an interpreting service on such a scale and with such a range of language combinations was put into operation, the interpreters were mostly inexperienced and unqualified for the task. There was also only time for a "10 day orientation course" before the interpreters had to begin providing an interpreting service (ibid:27). As Lotriet (1998:92) acknowledges, 
the lack of time to train interpreters for the TRC ... was one of the daunting challenges that had to be faced. The demand for the interpreters to start working was immediate and consequently there was not time to gradually get to know the field and to train the interpreters at a steady pace.

The majority of witnesses testified in their mother-tongues (Du Plessis and Wiegand 1998:29). This, coupled with the fact that very few mother-tongue speakers of Afrikaans and English could speak any of the other official languages (Lotriet 1998:93), necessitated that the interpreters interpret into English for the most part, even though English was generally not their mother-tongue, a practice not sanctioned by international interpreting convention. Furthermore, commissioners' questions to witnesses were chiefly asked in English and answered by the witness in his or her mother-tongue (Du Plessis and Wiegand 1998:26), and this placed additional demands on the interpreters who had to alternate rapidly between the two languages.

Du Plessis and Wiegand (1998:26-27) also refer to the fact that the narrative techniques of testifiers varied: some provided too much detail, others were not very coherent and yet others included explicit references to taboo topics or crude language. All of these factors, especially under the pressure of simultaneous interpretation, presented challenges for the interpreters.

Apart from the language competence and combination issues, the specific context of the TRC, and especially the Human Rights Violations (HRV) hearings, presented particular challenges for the interpreters. The testimonies were frequently "heavily laden emotionally" (ibid:26) and interpreters sometimes had difficulty maintaining a professional detachment. Du Plessis and Wiegand (1998:28) refer to an instance when an interpreter at a Bloemfontein hearing "interpreted with tears literally streaming down her face".

Additional pressure was placed on the interpreters by the fact that the hearings were accompanied by intense national and international media interest, including direct radio and television broadcast on SABC. According to Tutu (1999:84), "radio, TV and newspapers gave the TRC and its victim and amnesty hearings saturation coverage". 
The interpreters worked in teams of two and were meant to alternate every 20 minutes (ibid:28). Although the witnesses had prepared written statements in advance and the commissioners had copies of these documents in advance, it is not clear whether the interpreters had had access to these before the hearings. According to Du Plessis and Wiegand (1998:28), interpreters were supposed to receive the documentation 24 four hours in advance, but statements were "usually handed out at the start of the day, if at all, and background material (was) rarely provided". It can therefore be assumed that the interpreters were hearing many of the testimonies for the first time "live" and therefore were working under very challenging circumstances.

The HRV hearings opened in East London on 15 April 1996. They were presided over by Archbishop Desmond Tutu who began the event by lighting a candle to commemorate all those who had died as a result of the conflict of the past. This was followed by the reading of a roll of honour "commemorating those who had fallen" (Tutu 1999:85), followed by the singing of a hymn, a prayer and a welcome in which Tutu (1999:87) said,

We are charged to unearth the truth about our dark past; to lay the ghosts of that past so that they will not return to haunt us. And that we will thereby contribute to the healing of a traumatised and wounded people - for all of us in South Africa are wounded people - and in this manner to promote national unity and reconciliation.

The testimonies were then delivered. At the end of each day, the Chairperson summed up the day's proceedings and attemted to capture the mood of the day. In Tutu's (1999:89) words, "this was also an opportunity to affirm those who had testified as well as the communities from which they came, and to draw lessons for us all in this unusual journey which our nation was undertaking".

The testimonies which this paper analyses are those of two women who speak about the harassment and deaths of their husbands at the hands of the security branch in the mid1980 's. Before we turn to the analysis of these testimonies, however, it is important to reflect more broadly on how women testified before the TRC. 
In her insightful account of how women spoke of suffering at the TRC, Fiona Ross (2003:17) notes that two distinctive patterns became evident early in the process of the Commission's work:

The first was that although approximately equal proportions of men and women made statements, for the most part women described the suffering of men whereas men testified about their own experiences of violation. The second was that women who had been active in opposing the Apartheid State seldom gave public testimony.

Although women did not tend to foreground their own experiences of suffering, references to their personal suffering were there: "submerged, but structuring the form and cadence of their narratives, women spoke of the effects of their own lives on the ruptured lives of others" (ibid:46). Ross traces the development of a number of themes that typically emerge in the testimonies of women. For example, women frequently told of the disruption to family life that occurred at many levels as a result of the actions of the state or the political activities of loved ones, and of their attempts to secure and protect families under the harsh conditions imposed by apartheid (ibid:42-43). They also told of their pain when they were unable to protect and secure their family, and of the disruption of order and their changed expectations of the future as a result of their loss of a husband and bread winner or a son who would have provided for them in their old age. As Ross (2003:48) summarises,

hidden within women's words are narratives of the destruction of kinship, of the alteration of time's expected flow, of the power of economies in shaping experience, of the intrusion of the state, and of women's determined attempts to create and maintain families. Read together, the accounts describe the penetration of violence into everyday life.

She further argues that TRC definitions of violence and human rights abuse constructed a narrow understanding of the apartheid past and the kinds of abuse people suffered. Victims were defined as people who had suffered "gross violations of human rights" which were in turn defined as "killing, torture, abduction ... and/or severe ill treatment, or the conspiracy or attempt to commit such acts" (ibid:11). This had the effect, argues 
Ross (2003:11), of focusing the work of the Commission, for the most part, on violations of the body and of removing from the frame forms of more subtle violence and discrimination - the forms of abuse to which many women testified.

The themes and patterns referred to by Ross are evident in the testimonies we selected for analysis. These come from the second day of the HRV hearings, 16 April 1996, when three of the four widows of the men known as the Cradock Four gave their testimonies. Fort Calata, Sparrow Mkhonto, Sicelo Mhlawuli and Matthew Goniwe were murdered by the security branch on 27 June 1985 for their activities in mobilising resistance in Cradock. At the hearings, Mrs Goniwe gave her testimony in English, while the other three widows gave theirs in Xhosa. We have selected the testimonies of Mrs Calata and Mrs Mhlawuli for analysis.

While the widows were delivering their testimonies, there was simultaneous interpretation into English. These interpretations were later transcribed and published on the TRC website, and, as mentioned earlier, these transcripts are usually the only records available publicly. While audiovisual recordings of most of the testimonies exist at the SABC, they are difficult to access. We managed to obtain copies of the audiovisual tapes from the East London HRV hearings that provide a record of both the selected testimonies in the source language, Xhosa, as well as the simultaneous English interpretation as a voice-over. We transcribed the Xhosa testimonies, translated these into English and then compared these with the official English versions which are published on the TRC website. Our analysis of what has been lost in the official interpretation and transcription process is presented below. In each extract, we have first given the Xhosa transcription, then our English translation and then the official website version.

\section{Mrs Nomonde Calata's testimony}

The widows' testimonies generally begin with an account of who they are, when they met their husbands, where they lived and how many children they had. They then recount the incidents leading up to the death of their husbands: the formation of Cradora or Cradock Residents Association in 1983, their dismissals from their places of work as a result of their political activities, their detentions and harassment at the hands of the security branch and, finally, the disappearance of their husbands on Thursday 27 June 
1985. They then recall the period of anxiety and fear as they awaited news of their husbands and then of their distress and pain when their husbands' bodies are finally discovered. They recount in some detail the horror of their husbands' deaths as revealed through the post-mortem examinations.

The first extract from Mrs Calata's testimony comes at a point in her testimony when she recalls how, in May 1985, the security branch stopped Matthew Goniwe and Fort Calata's younger brother while they were driving and asked where Fort was. At the time, Fort was in Johannesburg receiving treatment for a frozen shoulder. (The sections of the extracts which are discussed in this paper are marked in bold for ease of reference. $^{2}$ )

\section{Extract 1}

\section{$\underline{\text { Xhosa transcription }}$}

Athi kubhuti Matthew "Mattewis waar is Meraai?" Ubhuti Matthew wabuza "ngubani uMeraai?" / Athi "uyilibele inkosikazi yakho uFort?" / athi ubhuti Matthew "uFort akasiyiyo inkosikazi yam he is a friend of mine" / lacommenta elinye lisithi "ons sal jou en Meraai weer kry as julle saam in die kar is"

\section{English translation}

They said to bhuti Matthew "Matthew where is Meraai?" Bhuti Matthew asked "who is Meraai?" / they said "have you forgotten your wife Fort?" / bhuti Matthew said "Fort is not my wife he is a friend of mine"/ the other one made a comment saying "we will catch you and Meraai again when you are together in the car"

\section{Website version}

They asked Matthew where Marai is. He asked who Marai is? And then they asked Fort if had forgotten his wife, Fort, sarcastically. They said, "We will get you again, you and Marai."

One of the most noticeable features of Mrs Calata's testimony is her distinctive narrative style: she uses direct speech and often quotes the words verbatim that were spoken to her by the police, despite the fact that she is recounting an incident that happened more 
than 10 years before. Her use of Afrikaans, the official language of the former apartheid government, characterises the police as part of the former security establishment and serves to dramatise the way in which the security branch culture penetrated and disrupted their lives. In the website version, the dialogue is shortened and the code switching into Afrikaans is lost.

Furthermore, in the website version, an interpretation error has crept in. The interpreter inserts the incorrect name: the first mention of Fort should have read Matthew in the sentence And then they asked Fort if had forgotten his wife, Fort, sarcastically. This not only has the effect of making the sentence puzzling and somewhat incoherent, but it obscures the sexual innuendo carried by the reference to Mattewis and Meraai. Mattewis and Meraai, a married couple, are well-known characters in Afrikaans literature and appeared in an Afrikaans television series which was showing in the mid1980's (Krog 1998:40). The sarcastic casting of Fort Calata as Meraai, the wife of Matthew Goniwe, can be seen as a security branch tactic to intimidate the men by attempting to feminise and sexually humiliate them.

In the following three extracts, there are several additional examples of how the meaning of a testimony can be distorted through the interpretation process. In Extract 2, Mrs Calata gives an account of the daily police harassment she and her family endured, namely that there was usually heavy police surveillance outside their home during the night. However, on the night that Fort Calata did not come home, there was not a single police van or armoured vehicle present. The lack of police surveillance on the night of Fort Calata's disappearance is interpreted by Mrs Calata as a sign that something is amiss. In the website version of Extract 2, however, the interpreter's account of events is opposite to the actual testimony.

In addition, the interpreter sometimes gives additional information which is not in the Xhosa transcript. For example, the website refers to a premonition that Mrs Calata had that night, which is not explicitly stated in the original testimony. 


\section{Extract 2}

\section{$\underline{\text { Xhosa transcription }}$}

Hayi, ndingakwazi ukulala, / ndiphume / usually xa uphuma ke pha endlini yam ebusuku uyakufika kukho iVan engxangileyo kukho iCasper emi kwelinye icala, kukho icawa e-opposite nendlu yam / uyakufika kukho iCaspir emileyo phaya kujongwe straight apha endlini / that evening kwaku quiet kwakungekho ne motor emove around / ndaqonda hey hayi, andinakukwazi ukulala / ndimithi ke isisu singaka [hand signal] / OK ke ... ndalala amehlo ndiwavulile

\section{English translation}

No! I could not sleep / I went out / usually when you go out of my house at night / you always see a police van standing by / and a Caspir standing on the other side / there is church opposite my house / you will see a Caspir standing there looking straight at my house / that evening it was quiet, there was not a single car moving around that evening / I realise hey! No! I cannot sleep / I am pregnant my belly is like this [hand signal] / OK right I slept with my eyes open

\section{$\underline{\text { Website version }}$}

So I kept on, I was awake suffering from insomnia. When I looked out, there was a caspar and vans. The casper was on the other street but not a single car moved around as they usually did. This was also an indication that something was wrong. I had this premonition and I was very expectant at the time. I still had insomnia.

In Extract 3, we see a third example of how the meaning is distorted and lost in the official website version. In the Xhosa testimony, Mrs Calata said that she only noticed the picture of the burnt out car on the front page of The Herald when her inquisitive child pointed it out to her. In the official version, however, it is said that she read the headlines and that one of the children said that he could see that his father's car was shown in the paper as being burned. This makes it appear as though it is Fort's car, but, as we hear in the Xhosa testimony, it was Matthew Goniwe's car. 


\section{Extract 3}

\section{$\underline{\text { Xhosa transcription }}$}

Ngomgqibelo bekudla ngokudeliver iHerald apha endlini yam / kuthe kuthengiswa i Herald / so iHerald i'deliver' kusasa Xa kudeliver le Herald, (.) eli phepha andiliboni nakakuhle / ndithi kuba ndinomntwana oqavileyo athi mama jonga apha ephepheni / xa ndisithi tyhini! Yimoto kabhuti Matthew mos le itshile (.) kwangoko ndingonwabi toe - ndiqale ndingonwabi. Xa itshile itshile imoto kabhuti Matthew ingaba kwenzeke ntoni kubo? / heyi hayi! ndingonwabi toe kungabikho mnandi / ndixelele ineighbours ukuba zibe zindinika amaphepha. Hayi ke kuthi ekuhambeni kwethuba (.) ndizokuthathwa (.) ngabantu zifriends zithi yiza man sukuba wedwa apha iya pha kuNyami because uNyami upha phezulu ebantwini bomzi wakhe / because uNyami was always there for me endiqinisa ndingumntwana I was only twenty - twenty five or so xa ndifika, uNyami ekhala apha [cries out loud]

\section{English translation}

Usually, the Herald was delivered to my house on Saturdays / the Herald was sold here / so the Herald was delivered in the morning / when this Herald was delivered I could not even see this paper clearly / Since I have this inquisitive child / she said mother look at this paper / when I looked tyhini! (in shock) this is bhuti Matthew's car is burnt / At that moment I felt uneasy I started realizing that something was wrong When Matthew's car is burnt what happened to them / hey! No! I became anxious and the situation was not good / I told my neighbours that - they also gave me a lot of papers Then after some while / people - friends came to fetch me / they said come on do not stay alone here / go to Nyami (Mrs Goniwe) because Nyami is up there with her in-laws because Nyami was always there for me / comforting me / I was young / I was only twenty - twenty five or / so when I arrived Nyami was crying there [cries out loud]

\section{$\underline{\text { Website version }}$}

Usually the Herald was delivered at home because I was distributing it. During the time that it was delivered I looked at the headlines and one of the children said that he could see that his father's car was shown in the paper 
as being burned. At that moment I was trembling because I was afraid of what might have happened to my husband, because I wondered, if his car was burned like this, what might have happened to him? I started distributing the papers as usual, but I was very unhappy because I was afraid of what might have happened to my husband, because I wondered, if his car was burned like this, what might have happened to him? I started distributing the papers as usual, but I was very unhappy. After a few hours some friends came in and took me and said I must go to Nyami, who was always supportive. I was still 20 at the time and couldn't handle this. When I got to Nyami's place Nyami was crying terribly and this affected me also. (sobbing)

At this point, the text itself is not very coherent, an indication of the distress she experiences as a result of reliving this particular episode: Mrs Calata repeatedly interrupting herself and it is at this point in her testimony that she is overcome by her emotions and begins crying uncontrollably, so much so that Archbishop Tutu adjourns the hearings to give her time to recover. Note that this "incoherence" is not evident in the website version.

In Extract 4, there is a further distortion and loss of meaning. If one reads only the website version, it is not at all clear what happens to Mrs Calata when she hears that the body of her husband has been found, nor the circumstances surrounding the visit to the doctor the following day. However, in the original Xhosa version, she clearly testifies that the shock of the news of her husband's death caused her unborn child to stop kicking and, as a result, her brother-in-law made an appointment for an emergency Caesarean the following day.

\section{Extract 4}

\section{Xhosa transcription}

Wafika ke umfundisi eze kuchaza ukuba imizimba (.) kaFort nekabhuti Matthew ifunyenwe (.) Hayi kwahlaleka ke (3) nda - ngelo xesha ke ndinomntwana owesibini inkwenkwanyana (.) Ebetshomene kakhulu ke notata wakhe. Uthe xa eyiva le nto ithethwa wagula, ndipregnant, wayeka nalo baby nokukhaba (?) andiyazi kwakusenzeka ntoni kum ngaloo mini. Umninawa kaFort ngaloo mini wandenzela iappointment kagqirha the following day. Into 
eyandimangazayo yeyokuba le ndaba ye appointment wayezama ukuyenza ukuba ibe secret ngolona lona hlobo / kodwa ndathi xa ndifika mna kwagqirha, ndafika kugcwele izecurity police kweli cala ndiza kungena kulo behleli pha. Endingayazi yeyokuba bebeze kujonga imeko yam injani na, kodwa ke waye wandixelela / "kuza kufuneka usule iinyembezi, uhlambe ubuso, uthi xa ungena pha ungene uhamba kakuhle" / alright ndamamela ke, ndahamba ke

\section{English translation}

The reverend arrived and told us that the bodies of Fort and Matthew had been found ... / I at that time I'm with my second child / a young boy / he was very close to his father / When he heard this / he got sick / I'm pregnant the baby just stop kicking / I do not know what was happening to me that day / Fort's younger brother made an appointment for me to see the doctor on the following day. What surprised me is the fact that Fort's brother was trying very hard to make this appointment as secretive as possible / but when I arrived at the surgery / the place was full of security police on this side where I was going to enter / they were sitting there / What I did not know was whether they came to see my condition or not / but he told me, "You have to wipe your tears / wash your face / when you enter you must walk straight" / then I listened and walked in

\section{Website version}

When I got home, the reverend from my church visited me. He had come to explain that the bodies of Fort and Matthew were found. At that time I had my second child, this child was very close to the father. After hearing this news the child was sick, I was pregnant at the time, I left the child that was inside of me, I don't know what happened to me on that day. An appointment was made with the doctor the next day, the thing I did not know was why this appointment was made so secretively, but when I arrived there, the security police were already there, just where I stepped in. I did not know if they were going to look at my condition, but she said to me, "Sister, you have to clean your face, wipe away the tears and be brave". And I listened. 
Extract 5 further illustrates how the emotional content is lost in the interpretation and transcription processes, as well as some of the inaccuracies which have crept in. It could be assumed that, for most people, the fact that their husbands had had their hair and tongue pulled out and their fingers cut off during torture would have been the most distressing aspect of their death. However, as is evident from the intonation on the audiovisual record, Mrs Calata foregrounds the fact that her husband was severely bitten by the dogs. It is possible that this indicated to her the utter disrespect that those who killed her husband had for him as a human being. In the official version, the repetition and the emphasis in this part of the testimony is lost: the sentence it looks like he was bitten by the DOG/(.3) there is nothing that made me feel bad more than knowing that he was also bitten by the DOG / that made me feel very bad is reduced to the dogs already had their share. In addition, on the website transcription, it reads as if it is Mr Gxuluwa, not Mrs Calata, who expressed his shock that Fort Calata had been bitten by the dogs. We also note a spelling mistake of Mr Gxuluwa's name in the website version.

\section{Extract 5}

\section{$\underline{\text { Xhosa transcription }}$}

Qha ke wasweleka u Mr Gxuluwa esasimcelile thina as ifamily aye ku identify Wabuya ke wandixelela ukuba (.) hayi ubonile - uye waqiniseka ukuba ngu Fort lowa / kodwa ufumanise into yokuba uxhwithiwe iinwele - zixhwithiwe literal ukuxhwitha iinwele entloko, ulwimi lwakhe lutsaliwe [hand signal] lalude ngaphandle, bamsika iminwe / enamanxeba amaninzi emzimeni / xa emjonga apha ebhulukhweni wafumanisa ingathi esiqulubeni utyiwe nayiNJA (.3) akukho nto yandenza buhlungu njengento yokufumanisa ukuba utyiwe naziziNJA/ yandenza buhlungu gqitha loo nto leyo

\section{English translation}

But Mr Gxuluwa whom, as family, we asked to go and identify the bodies / has passed away / He came back and told us that / he saw - he is quite sure that it was Fort / but he discovered that the hair had been pulled out / the hair had been pulled out deliberately / to pull the hair out of the head/ the tongue was pulled out of the mouth [hand signal] it was long out of the mouth / fingers were cut off / He had many wounds in his body / when he looked at his trousers he 
discovered that it looks like he was bitten by the DOG / (.3) there is nothing that made me feel bad more than knowing that he was also bitten by the DOG / that made me feel very bad

\section{$\underline{\text { Website version }}$}

Mr Koluwe, the man we as families asked to go and identify the bodies, has passed away. He said that he had seen the bodies but he discovered that the hair was pulled out, his tongue was very long. His fingers were cut off. He had many wounds in his body. When he looked at his trousers he realised that the dogs had bitten him very severely. He couldn't believe it that the dogs already had their share.

\section{Mrs Nombuyiselo Mhlawuli's testimony}

Sicelo Mhlawuli was active in student politics during the 1970's and 1980's and was a friend of Matthew Goniwe. Originally from Cradock, Sicelo and Nombuyiselo Mhlawuli had first lived in Dimbasa and then moved to Oudtshoorn in 1981, where they were both teachers. In 1985, they visited Cradock during the June school vacation. Mrs Mhawuli first became aware of her husband's disappearance when he did not arrive in Port Elizabeth to collect her from her winter school course. She finally read of their disappearance in The Herald on Friday 28 June 1985. She thought that her husband must have been detained and was worried about whether he had sufficient warm clothes for the cold police cells. Extract 6 is from the point in her testimony where she recounts speaking to her sister-in-law on the morning of 28 June, before she has returned from Port Elizabeth and before she has heard the news of her husband's death.

Like Mrs Calata, Mrs Mhlawuli often uses direct speech in her testimony, an indication of how these events are etched in her memory. In the website transcription, however, the instances of direct speech are mostly given as reported speech, once again leading to a loss of narrative immediacy.

In Extract 6, two items of significance have also been omitted from the website version. Firstly, the word waphinda ("again") has been omitted. This word shows that Lindiwe (the sister-in-law) and Mrs Mhlawuli had already been in contact on the matter of her husband's disappearance. Secondly, when Lindiwe speaks to Mrs Mhlawuli, she uses 
terms of respect, such as $u$ Bhuti and Sisi, which is evidence of the close relationship among the family members. Without these details, a reader of the website version might assume that the Mhlawuli family had had little or no contact with Mrs Mhlawuli prior to the Friday and a reader would not pick up on the closeness and intimacy within the family.

\section{Extract 6}

$\underline{\text { Xhosa transcription }}$

NgoLwesihlanu waphinda wandifowunela usister-in-law wam uLindiwe / efuna ukuqonda ukuba "uBhuti selefikile na Sisi?" / I think yena wayefuna ukujonga ukuba ndazi kangakanani ngale nto / ndithi "Lindiwe andiyazi / into endiyibonileyo liphepha eli (Herald ) nina nazintoni?" / athi "Sisi hayi akukhonto siyaziyo" / ndithi ke mna ke iphi imoto yakhe / kuthwe "hayi ikhona imoto nesitshixo sikhona" / ndithethe notatazala my father-in-law / ndimxelela ukuba tata please torhwana ndicela nizame indlela nizo kundiphuthuma / sendifuna ukubalapho ekhaya nam ngoku / nyani ke shame utata wathumela ubrother-in-law wam olapha ngoku naye (uMantiri) / kunye ne friends zakhe bazokundithatha / ndagoduka ngoLwesihlanu (.3)

\section{English translation}

So on Thursday / my sister-in-law Lindiwe called me again / trying to find out "Has uBhuti (brother) arrived Sisi (sister)?" / I think she was trying to find out how much do I know about this / I said Lindiwe, "I don't know/ the only thing I have seen is a newspaper (Herald ), what about you, what do you know" / then she says "no Sisi we know nothing" / then I asked "where is his car?" / they said "no the car is here as well as the key" / I talked to my father-in-law / asking if they could organise a car to fetch me / I want to be home now / he sent my brother-in- law (uMantiri) who is also here today, with friends to come and fetch me / then I went home on Friday (.3)

\section{$\underline{\text { Website version }}$}

On Friday my sister-in-law phoned me to find out if my husband was here, I think she wanted to find out how much I knew about his disappearance, but when I asked them they again said they didn't know anything. I asked her where 
the car was, and they said it was there as well as the key. I asked my father in law to please arrange that I should be taken back home, because I was already anxious, having this premonition that something has happened. I was fetched by my father-in-law and some of the friends on that Friday.

In the last two lines of Extract 6, there are two further problems: firstly, some information has been inserted into the website transcription which is not in the original, namely that Mrs Mhlawuli was anxious and had a premonition that something had happened. Secondly, it is said in the website version that her father-in-law and some of his friends fetched her, wheras in fact, as we can see from the Xhosa version, the fatherin-law sent his son (that is, Sicelo's brother and her brother-in-law) to fetch her. It is very unlikely that the father-in-law would have fetched her himself as, according to Xhosa culture, the father as the most senior member of the family should remain at home to welcome people who come to share their grief or sympathise with the family after a tragedy. A reader of the website version who is familiar with Xhosa traditions might therefore find the father-in-law's actions unusual.

In Extract 7, Mrs Mhlawuli recounts how her father-in-law went in search of his son's body and the way in which he reported on this to her. Here we have further evidence of the close relationship between Mrs Mhlawuli and her husband's family. Mrs Mhlawuli refers to her father-in-law as uTata ("father") and he refers to her as mntwana wam meaning "my child". Although these terms are sometimes carried through to the website version, they are generally not (usually the terms father-in-law and daughter-in-law are used) and the reader of this official version might miss the closeness of the relationship between father and daughter-in-law.

In Extract 7, we also have an example of a Xhosa word for which there is no direct equivalent in English and, under the pressure of simultaneous interpreting, the interpreter is unable to express the full meaning of the word. The interpreter interpreted the word ingqushu as "something very suspicious", but perhaps a more accurate phrase could have been "like a battlefield", meaning that the place where they killed $\mathrm{Mr}$ Mhlawuli was full of blood, debris and signs of violence and fighting. 


\section{Extract 7}

\section{$\underline{\text { Xhosa transcription }}$}

Utata, my father-in-law / wayekhona / kwigroup eyayihamha ifuna le mizimba naye / uthi xa endixelela "Nolitha mntwana wam/ ndiyibonile indawo abambulele kuyo umntwanam / bekukho ingqushu kula ndawo/ engumangaliso / yaye igazi lakhe eliphaya lininzi / and kuyacaca ukuba bambulele/ bamtshisela kwakula ndawo ..."

\section{English translation}

My father, my father-in-law was also in that group / that went to look for these bodies / he says to me, "Nolitha my child / I saw the place were they killed my child / it was like a battlefield there / there is a lot of his blood there / and it's evident that they killed him / and burned him there ..."

\section{$\underline{\text { Website version }}$}

My father-in-law was among the group that was searching for the bodies. And he said, "Nolita, my child, I saw a place where they killed my son. There was something very suspicious, there was blood. It is clear that they killed him, they burned him at the same place ..."

Extract 8 directly precedes what is for Mrs Mhlawuli the most difficult point in her testimony, evidenced by the fact that she breaks down and cries after recounting this episode. It tells of what her father-in-law said to her on his return from his visit to the mortuary to identify Mr Mhlawuli's body. He describes the condition of the body. In the original Xhosa, Mrs Mhlawuli repeats the words he used to her as direct speech, and the phrase my child is repeated six times, which could be seen as an indication of the love the father-in-law had for Sicelo and Mrs Mhlawuli and of how he was hurt by what was done to his child. In the website version, these repetitions of my child are realised only as pronouns, and thus the emotional intensity of the testimony is lost.

\section{Extract 8}

\section{$\underline{\text { Xhosa transcription }}$}

Mrs MHLAWULI: ... I suppose inokuba zazikhona ne remarks ebabezenza / but baya bafika phaya bajonga / utata wafumanisa ukuba Tyhini! Nguye nyani 
uSicelo lo / uthi "mntwana wam imeko akuyo" / wandixelela ukufika kwakhe wathi / "mntwana wam imeko akuyo/ iyoyikisa / umntwana wam bamtshisile umntwana wam, umntwana wam bambulele kabuhlungu umntwana wam" [cries] (.4)

Mr Sмiтн: Are you - are prepared to continue Mrs Mhlawuli?

\section{English translation}

Mrs MHLAWULI: ... I suppose they also made certain remarks / but they went there and looked / my father found that Really! It is him, Sicelo / he says "my child the condition that he is in" / he told me on his arrival and said / "my child the condition that he is in / is frightening / my child they burned my child / my child, they killed my child horribly" [cries] (.4)

MR SMITH: Are you - are you prepared to continue Mrs Mhlawuli?

\section{Website version}

Mrs MhlawUli: ... I understand there were also remarks. My father in law had a look and confirmed that one was Sicelo. He said the condition in which he was in was really shocking. They had burned him terribly.

MR SMITH: Are you prepared to continue?

The fact that Mrs Mhlawuli cried after recalling what her father-in-law said is not reflected in the website transcription. This could also prevent the reader from being aware of the emotions that she felt as she was recalling the event.

We also found that the commissioner's questions are often edited in the official version, which makes them appear short, clipped and insensitive to the testifier's feelings. The false starts and hesitations as shown above in Extract 8 indicate empathy and concern for the testifier. After Mrs Mhlawuli has spoken, Mr Smith, the commissioner, wants to proceed but finds it difficult to continue because Mrs Mhlawuli is crying, and hence his hesitation, Are you - are you prepared to continue...? From his intonation, facial expression and bodily posture, his compassion is also apparent, but this is lost in the official version. 
Occasionally, we have noticed that the transcriber has changed or inserted words that were not in the simultaneous translation. For example, in Extract 8, the transcription reads the condition in which he was in was really shocking. However, the interpreter on the day used the term "disappointing". We have translated the Xhosa word iyoyikisa as "frightening". It could be that the transcriber felt that disappointing sounded too mild in this context and so changed it. This and the interpretation of ingqushu as "something very suspicious" serve as two examples of the tendency we noted among the interpreters to avoid taboo words and to "tone down" words with strong connotative meaning, thereby decreasing the intensity of what was expressed by the narrators.

In Extract 9, there is a further example of this kind of toning down when Mrs Mhlawuli describes how she felt when she read her husband's post-mortem report. Her words are that she was very hurt. The interpreter interprets this as "very worried". Mrs Mhlawuli then tells of her husband's wounds and of the distressing fact that his right hand was missing. Two things are of note here: firstly, that there is a transcription error and, secondly, that a vital piece of information has been omitted from the official version.

Concerning the transcription error, on the day of the hearing, the interpreter correctly interpreted Mrs Mhlawuli as saying that her husband had 25 wounds in the upper abdomen. However, the transcriber of the official version only recorded five, which underplays the severity of the wounds as well as the event in general. In addition, at the end of the extract, the interpreter omits a very important detail, namely that Sicelo Mhlawuli was buried without his right hand. In many African cultures, it is believed that if a person is buried without a body part, he or she will not rest in peace and there could be serious consequences for the homestead. Therefore, for a Xhosa person, the detail that he was buried without his right hand is a serious and culturally significant detail.

In the Xhosa version, her sentence simngcwabe ngaphandle kwewrist yakhe yase right / right arm or whatever / hand actually ("we buried him without his right wrist / right arm or whatever / hand actually") is a little incoherent, which could reflects the fact that this detail is very difficult or painful for her to talk about. Once again, this indication of emotional distress is lost in the official version. 


\section{Extract 9}

\section{$\underline{\text { Xhosa transcription }}$}

Yes, Mr Matthew - Mr Smith / I went through - ndazifunda iidocuments ezepost-mortem / apha ekuzifundeni kwam / ndakhathazeka kakhulu / ngoba kaloku yona ichaza in detail yonke into eyenzekayo / ndazifunda / ndafumanisa into yokuba lo mfo / wayenamanxeba amaninzi angumangaliso emzimbeni wakhe / kwi upper abdomen waye na about twenty-five wounds / iwounds ezazichaza into yokokuba different sizes of weapons were used / to stab him / okanye a group of people stabbed him / and the kwilower parts zakhe wayenezinye / but all together iwounds awayenazo zaziyi forty-three / and enye into esiyiqondayo ukuba yenzeka kuye / bamgalela i-acid emehlweni ache / bakugqiba bamqhawula isihlahla sakhe sasekunene / simngcwabe ngaphandle kwewrist yakhe yaseright / right arm or whatever / hand actually / asazi ukuba basithini isandla eso

\section{English translation}

Yes, Mr. Matthew - Mr. Smith / I went through - I got the post mortem documents / as I was reading them / I got very hurt / because they stated everything in detail / I read them / and I found out that this man/ had many unbelievable wounds in his body / he had twenty-five wounds in his upper abdomen / wounds which showed that different sizes of weapons were used / to stab him / or a group of people stabbed him / and then in his lower parts of the body he had others / but all together he had forty-three wounds / and another thing that we think happened to him is that / they poured acid in his eyes / and then they chopped off his right hand / we buried him without his right wristright arm or whatever / hand actually / we don't know what they did with the hand

\section{$\underline{\text { Website version }}$}

I read the post mortem documents. Reading them I was really worried, because it has to explain in detail what happened. I read through and came to understand that he had many wounds, in the upper abdomen were five wounds, these wounds indicated that different weapons were used to stab him or a group of people stabbed him. Now in the lower part he also had wounds but the wounds 
in total were 43. One other thing that we understood, they poured acid on his face, after that they chopped off his right hand, just below the wrist, I don't know what they did with that hand.

\section{Conclusion}

From the above discussion, it can be seen that an interpreter is faced with a challenging task: he or she has to play a dual role of the speaker, or multiple speakers, as well as the interpreter. This is particularly problematic in the case of the TRC hearings. The emotional content of the testimonies puts the interpreters under severe pressure. The interpreters had to switch roles between that of the TRC official and the witness, and had to filter the different emotions of the speakers through their interpretations. At times, they had to struggle with moments in which language seemed inadequate to express the extent of the pain, all under real-time pressure. They had to take into account not only what was said by the testifiers, but also the contextual information, in order to give the testimonies an appropriate interpretation. As Gutt (1991:72) puts it, "in verbal communication the derivation of the speaker-intended interpretation depends not only on correct decoding, but just as much on the use of the right, that is speaker intended, contextual information".

Some of the contextual information which would have played an important role in these testimonies includes the nature of the hearings, the culture of the testifiers, the facial expressions and gestures, the intonation, repetition and direct speech. However, we find that in the official version much of this information has not been conveyed. In summary, our analysis of the testimonies of Mrs Calata and Mrs Mhlawuli demonstrates that the following kinds of information have been lost:

Firstly, there has been a loss of culturally significant details, such as the fact that $\mathrm{Mr}$ Mhlawuli was buried without his right hand, as well as the nature of the relationships indicated through the use of the terms of respect such as uBhuti, uSisi, and uTata.

Secondly, significant emotional content or, in the terminology of the TRC, "narrative or personal truth" is lost. Features which contribute towards this include the following:

(i) There is a loss of direct speech and the narrative immediacy that this brings, such as the verbatim quotes in Afrikaans from the police. Other markers of emotion 
are also lost in this process, such as Mrs Calata's cry Tyhini! Yimoto kabhuti Matthew mos le itshile! ("Tyhini! (in shock) This is bhuti Matthew's car is burnt!")

(ii) There is the loss of repetition and resultant loss of emotional meaning, as in the lament of Mr Mhlawuli senior, umntwana wam, umntwana wam ("my child, my child").

(iii) Further emotional content is lost when the interpreters tone down the content of the testimony, such as the interpretation of ndakhathazeka kakhulu as "I was really worried" instead of as "I got very hurt".

(iv) At times, there is a lack of equivalent terms and a subsequent loss of meaning, such as ingqushu for which the closest English equivalent is the word battlefield. In such cases, the use of non-equivalent words may not accurately reflect the extent of the trauma experienced by the narrator of the event.

Thirdly, there is a loss of factual truth when some material is not included (such as the fact that Mr Mhlawuli was buried without a right hand) and when some material is inaccurately interpreted (such as the presence of Caspirs in the street outside Mrs Calata's house on the night of her husband's disappearance). We also noted that some factual errors crept in during the transcription process, such as the fact that the official version records five instead of 25 wounds in the upper abdomen of Mr Mhlawuli.

Lastly, paralinguistic information communicated through gesture, intonation and facial expressions is also lost, such as the way in which Mrs Calata foregrounded the painful memories of the dog bites to her husband's legs.

Ross (2003), in her analysis of women's testimonies, describes the HRV hearings as "emotional events ... a public performance of memory, loss and grief" (ibid:15) and suggests that "the communication of pain rests on words, gesture and silence" (ibid:49). She argues that women's suffering is already marginalised by the definitions of "victim" and "gross violation of human rights" which the TRC adopted. The loss of factual and narrative truths described in the analyses above further diminishes the extent of loss and trauma experienced by these women. Whereas the official versions of these testimonies give us an adequate record of what was narrated, significant information has been lost through the interpreting and transcription processes. This ultimately results in a less 
than complete picture of the events as experienced by Mrs Calata and Mrs Mhlawuli. Part of the purpose of this paper was to recover some of these meanings.

It should be noted, however, that the findings referred to above cannot be generalised to all testimonies, as a number of factors may have affected how well the interpreter captures the testifier's meaning on any one occasion. For example, a testifier's narrative style may affect the ability of the interpreter to interpret accurately; emotionallycharged testimonies, delivered at a more rapid rate, may pose greater challenges. In addition, specific language combinations, such as Afrikaans into English, or testimonies given at a later date in the life of the Commission, may have had the advantage of more experienced interpreters and thus resulted in less loss of meaning.

In closing, we also wish to emphasise that we did not undertake this research so as to point to the deficiencies of the TRC interpreters, who under very difficult circumstances performed an extraordinary service of national significance. Rather, we wish to demonstrate that the official record should be read with caution and that researchers working on the TRC testimonies would be advised to consult the original testimonies in the languages in which they were given if they are to do justice to the people who testified at the Truth and Reconciliation Commission and to understand their stories in their fullest sense. 


\section{Notes}

* We would like to thank Mary Bock for assisting us with access to audiovisual tapes and for comments on an earlier draft of this paper. We are also grateful to Antjie Krog for her encouragement and for her input on the analysis of the transcripts.

1. The TRC transcripts are available online at http://www.doj.gov.za/trc.

2. The transcription key is as follows:

/ utterance boundary

- $\quad$ self-interruption

(.) slight pause

(.3) pause length in seconds

CAPITALS emphasis 


\section{References}

Du Plessis, T. and C. Wiegand. 1998. Interpreting at the hearings of the Truth and Reconciliation Commission: April 1996 to February 1997. In A. Kruger, K. Wallmach, and M. Boers (eds.) Language facilitation and development in South Africa. Pretoria: Blue Chip Printing Services.

Gutt, E. 1991. Translation and relevance: cognition and context. Oxford: Blackwell.

Krog, A. 1998. Country of my skull. Johannesburg: Random House.

Lotriet, A. 1998. Interpreter training in South Africa: needs and challenges. In A. Kruger, K. Wallmach, and M. Boers (eds.) Language facilitation and development in South Africa. Pretoria: Blue Chip Printing Services.

Ross, F.C. 2003. Bearing witness: women and the Truth and Reconciliation Commission in South Africa. London: Pluto Press.

SABC Video footage: TRC East London 16/4/96. Tapes 2 and 3.

Truth and Reconciliation of South Africa Report, Vol. 1. 1998. Cape Town: TRC Commission. Distributed by Juta and Co Ltd.

Tutu, D. 1999. No future without forgiveness. London: Rider.

Verdoolaege, A. 2002. The Human Rights Violations Hearings of the South African TRC: a bridge between individual narratives of suffering and a contextualising master-story of reconciliation. Paper presented at Transaction of Public Culture Workshop, University of Cape Town. 